Luz Marina Nana

Rodríguez Romero

mantegna_co@yaboo.com

Docente Escuela de Filosofía

Universidad Pedagógica y

Tecnológica de Colombia (Uptc)

Grupo de investigación: Si mañana

despierto, Uptc

Artículo de reflexión

Fecha de recepción:

15 de septiembre de 2010

Fecha de aprobación:

10 de noviembre de 2010

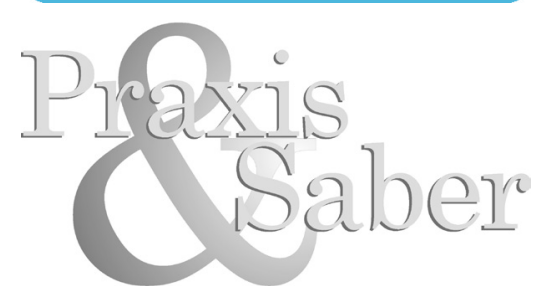

Revista de Investigación y Pedagogía Maestría en Educación. Uptc

\section{EL CINE, ESTRATEGIA \\ PARA EL DESARROLLO DEL PENSAMIENTO}

FILM: A STRATEGY FOR THE DEVELOPMENT OF THINKING

LE CINEMA, UNE STRATEGIE POUR LE DEVELOPPEMENT DE LA PENSEE

O CINE, UMA ESTRATÉGIA PARA O DESENVOLVIMENTO DO PENSAMENTO. 


\section{Resumen}

El trabajo investigativo que presenta este artículo se desarrolló dentro de la Línea de Innovaciones Pedagógicas de la Maestría de Educación de la Uptc, en el año 2009; su objetivo principal fue diseñar y aplicar una estrategia basada en el cine, que permita hacer rupturas con la imagen dogmática del pensamiento en los estudiantes universitarios, y su diseño metodológico se enmarcó dentro de la investigación-acción, con un enfoque socio-crítico, que permitió construir unos referentes teórico-conceptuales respecto de los temas de la innovación educativa, el cine-pensamiento y el concepto-imagen. También se desarrolló la innovación pedagógica mediante una prueba piloto y se realizó el análisis de la información. Se concluyó que el cine es un instrumento valioso para desarrollar el pensamiento por medio del trabajo con el concepto-imagen. Las formas de pensamiento que se observaron a través de este ejercicio de innovación fueron el desarrollo del pensamiento crítico y reflexivo por medio de la comprensión del mundo, y de la naturaleza del ser humano, contextualizando las problemáticas de las películas y fortaleciendo las relaciones comunicativas entre docente y estudiantes.

Palabras clave: Innovación pedagógica, comunicación, cine, pensamiento, concepto-imagen.

\section{Abstract}

The present project, developed in 2009, is framed in the Pedagogical Innovations research line of the Education Masters Program of Universidad Pedagógica y Tecnológica de Colombia. The main objective was to design and apply a strategy in order to break the dogmatic image of thinking in university students, through the use of film. This action research project with a socio-critical approach, is grounded in theoretical and conceptual references concerning educational innovation, film-thinking and image-notion. Moreover, this pedagogical innovation was carried out using a pilot test as data analysis tool. It was concluded that film is a meaningful instrument for the development of thinking, given that students work with concepts and images. Critical thinking and reflection were the result of this educational innovation, which allowed students a deeper comprehension regarding the world, nature and the human being. One of the most important aspects achieved was that students were able to link real life with 
the fictional problems shown in the films; relationship between teacher and students also became stronger.

Key words: pedagogical innovation, communication, film, thinking, image-notion.

\section{Résumé}

Cet article présente un travail de recherche qui a été développé dans le cadre d'Innovations Pédagogiques de la Maîtrise en Education de l'UPTC, en 2009. Son objectif principal a été celui de designer et appliquer une stratégie, basée sur le cinéma, pour permettre de faire des ruptures avec l'image dogmatique de la pensée chez les étudiants universitaires. Son design méthodologique s'est encadrée dans la recherche-action, avec une focalisation socio-critique qui a fait possible la construction des référents théorique-conceptuels par rapport aux sujets de l'innovation éducative, le cinéma-pensée et le concept-image. On a aussi développé l'innovation pédagogique ‘a partir d'un essai pilote et on a fat l'analyse de l'information. On a conclut que le cinéma est un instrument important pour développer la pensée `a travers le travail avec le concept-image. Les formes de pensée qui ont été observées `a travers cet exercice d'innovation, ont été le développement de la pensée critique et réflexive `a partir de la compréhension du monde, et de la nature de l'être humain, en donnant un contexte aux problématiques des films et en renforçant les rapports communicatifs entre les enseignants et les étudiants.

Mots clés: Innovation pédagogique, communication, cinéma, pensée, concept-image.

\section{Resumem}

O trabalho de pesquisa que se apresenta neste artigo estão dentro de desenvolvimento de a Línea das Inovações Pedagógicas da Maestria da UPTC, em el ano 2009: seu objetivo principal foi desenhar e aplicar uma estratégia baseada no cine, que permita fazer rupturas com a imagem dogmática do pensamento nos estudantes universitários, e seu desenho metodológico enmarcou-se dentro da investigação -ação, com um enfoque sócio-crítico, 
que permitiu construir uns referentes teórico-conceptuais respeito dos temas da inovação educativa, o cine-pensamento e o cine-imagem. Também se desenvolve a inovação pedagógica mediante uma prova piloto e logo se realizou a análise da informação. Concluiu-se que o cine é um instrumento valioso para desenvolver o pensamento por médio do trabalho como o conceito-imagem. As formas do pensamento que se observaram a través deste exercício de inovação foram o desenvolvimento do pensamento crítico e reflexivo mediante a compressão do mundo, e da natureza do ser humano, contextualizando as problemáticas das películas e fortalecendo as relações comunicativas entre docente y estudiantes.

Palavras chave: inovação pedagógica, comunicação, cine, pensamento conceito-imagem.

\section{INTRODUCCIÓN}

En el año 2009 se desarrolló, como requisito para optar al título de Magíster en Educación, en la Uptc, el trabajo de investigación e innovación que aquí se presenta, cuyo tema fue las innovaciones pedagógicas en el campo de la comunicación a través del cine, como estrategia para el desarrollo del pensamiento desde la perspectiva de la reflexión, la crítica y el debate en el aula de clase. Las innovaciones educativas son hasta ahora un tema muy poco explorado en el ámbito de la educación universitaria, a pesar de que se ha expandido en la educación básica y media, a través de las prácticas pedagógicas en las áreas de las didácticas y del currículo. La innovación en las universidades colombianas se ha orientado hacia la investigación para la producción de conocimiento, para el desarrollo de tecnología y de ciencia y para el desarrollo social e institucional, respecto de las necesidades del entorno, de acuerdo con las políticas del Estado.

El objetivo general de este trabajo de investigación y de innovación pedagógica fue diseñar y aplicar una estrategia pedagógica que permita hacer rupturas con la imagen dogmática del pensamiento en los estudiantes universitarios, por medio del cine; con tal motivo, y como objetivo específico, se optó por la construcción de unos referentes teórico-conceptuales que permitieran sustentar que el cine se puede utilizar como una innovación para el desarrollo del pensamiento, y elaborar una metodología a través de actividades y prácticas con los estudiantes. 
El sentido y significado de esta investigación fue ofrecer un aporte al debate actual sobre la definición del concepto de innovación educativa, un aporte desde la práctica y la reflexión pedagógica a través del diseño de la estrategia; además, hacer un aporte a la Linea de investigación en innovaciones pedagógicas, de la Maestría de Educación de la Uptc.

En lo personal, el propósito es continuar con este trabajo en la cotidianidad del aula de clase y en el trabajo con el semillero de investigación, pues por tratarse de una innovación pedagógica, concebida como un proceso reflexivo y práctico, es susceptible de ajustes y cambios, y también de incertidumbre, dado que se trabaja con seres humanos, que son complejos y muchas veces impredecibles.

\section{METODOLOGÍA}

Este trabajo investigativo y de innovación pedagógica se enmarcó dentro de una investigación de corte cualitativo, con un enfoque socio-crítico de Investigación-Acción. En el enfoque socio-crítico, la relación sujeto-objeto es compromiso del investigador, en este caso del docente, que se convierte en un sujeto más; la finalidad del conocimiento que allí se produce busca el cambio y la emancipación de los sujetos, y la articulación y secuencia de los momentos investigativos responden a unos supuestos teóricos, un diagnóstico, una teoría y una reflexión, que se pueden evidenciar en este trabajo. Por otra parte, en este ejercicio la teoría y la práctica son indisociables; la práctica es teoría en acción y el análisis de datos es intersubjetivo y dialéctico, con base en los textos escritos por los estudiantes, como fruto de la experiencia de innovación.

La ruta que se construyó para este trabajo consta de varios momentos. El primero tuvo que ver con el planteamiento del problema, en cuanto a la problemática de la educación tradicional, en la que no se enseña a pensar, sino a transmitir información y repetir el saber construido por otros a través de la historia; la pregunta que se abordó fue: ¿cuáles son las formas de pensamiento que se evidencian en los estudiantes universitarios a través del cine, mediante el concepto-imagen? También, la redacción de objetivos.

En el segundo momento se adelantó el acopio y construcción de unos referentes teóricos y conceptuales que fundamenten la innovación propuesta. Con este propósito se trabajó con 
los estudios sobre innovación educativa a partir del trabajo de Blanco y Messina (2000), para Latinoamérica; De la Torre (1997-98), en España, y el IDEP (1999), en Colombia. Para el caso de esta investigación se propuso la innovación inicialmente como una fisura, en el sentido de que no es sencillo hacer rupturas radicales de entrada, sino que los pequeños cambios, en este caso, las fisuras, van abriendo grietas de donde pueden surgir imprevistos y novedades que no estaban contempladas; pues los procesos de esta índole son inciertos, como ya se dijo, por tratarse de seres humanos muchas veces impredecibles; entonces, los pequeños cambios, con el tiempo y las tensiones que allí se producen, provocan rupturas en los procesos educativos de estudiantes universitarios y en las prácticas pedagógicas de los docentes. También se trabajó con el pensamiento crítico de Estanislao Zuleta (2004a, b), respecto de la definición del problema, en lo relacionado con enseñar a pensar; con Freinet (1974), McLuhan (1969), Barbero (2003) y Ferrés (1993-2000), entre otros autores, para el tema de la era de la tecnología y las comunicaciones, y con Alan Badiou (2004-2009), Deleuze (2000) y Cabrera (1999), respecto de la relación cine-pensamiento. El concepto-imagen elaborado por Julio Cabrera expresa que se instaura dentro de un contexto y una experiencia, se trata de un lenguaje instaurador que exige pasar por una experiencia para ser consolidado; no se trata de tener informaciones, sino de dejarse afectar, una comprensión que solo podrá realizarse viendo el filme, lo que constituye una experiencia emocional que no puede proporcionar la lectura de la sinopsis o el comentario; más allá de la experiencia estética, el concepto-imagen otorga una dimensión comprensiva del mundo (Cabrera, 1999, pp. 18-19). Los conceptos-imagen del cine, a través de esta experiencia instauradora, buscan producir en alguien un impacto emocional, dice Cabrera, que al mismo tiempo le diga algo acerca del mundo, del ser humano, de la naturaleza, que tenga un valor cognitivo, persuasivo y argumentativo a través de su componente emocional (p. 20). Además, los conceptos-imagen afirman algo sobre el mundo con pretensiones de verdad y de universalidad, puesto que el cine no elimina la verdad o la universalidad, sino que las redefine dentro de lo que el autor llama la razón logopática, es decir, la lógica y la emoción.

El tercer momento estuvo relacionado con el diseño de la innovación pedagógica, que incluyó un diagnóstico. En el cuarto momento se aplicó la innovación a través de una prueba piloto con un grupo focal de análisis integrado por nueve estudiantes, para recoger la información requerida a través de textos escritos y conversatorios para socializar, y, por último, se desarrolló el análisis de la información y se sistematizó la experiencia en general. 
La población estuvo constituida por nueve estudiantes del programa de Psicopedagogía de la Uptc, integrantes del semillero del grupo de investigación Rizoma; ocho mujeres y un hombre, quienes cursaban el séptimo semestre y provienen de diversas poblaciones de Boyacá.

Para iniciar esta experiencia se diseñó una prueba piloto que, a su vez, se desarrolló en varias etapas o momentos. Para comenzar, se seleccionaron cuatro películas, con el propósito de observarlas: La lengua de las mariposas, Batman: el caballero de la noche, Matrix y Memento (amnesia). Los criterios para esta selección estuvieron fundamentados en que son películas de tipo comercial, es decir, no necesariamente están catalogadas como cine-arte o cine-conceptual; la propuesta es que este modelo basado en el concepto-imagen puede ser aplicado a cualquier tipo de película, pues el cine, al estar constituido por imágenes, nos permite conjugar conceptos y emociones. También se considera que estas películas crean rupturas con la forma tradicional de las narrativas cinematográficas, por cuanto en ellas el manejo del tiempo no es lineal; por ejemplo en Memento. Por otra parte, La lengua de las mariposas fue elegida para hacer una especie de diagnóstico sobre la manera como los estudiantes perciben y re-construyen una película.

En segunda instancia, se les explicó a los estudiantes que intervinieron en el ejercicio el sentido de la práctica, los objetivos y la metodología de trabajo, al igual que algunos conceptos sobre cine y técnicas cinematográficas, como el de planos, movimientos de cámara y secuencias, entre otros; también se les indicó las películas por observar.

En la primera sesión se trabajó la película La lengua de las mariposas, que algunos de los estudiantes ya habían visto, y se les pidió escribir un comentario personal sobre ella. En la segunda sesión se desarrolló un conversatorio para socializar el comentario de cada uno de los participantes, y además se explicó el concepto-imagen, con sus características esenciales, que después se aplicó sobre la misma película, para que los estudiantes tuviesen un referente. En las siguientes sesiones se observaron las tres películas elegidas, se realizó el respectivo conversatorio para cada una de ellas y los estudiantes elaboraron textos escritos con el concepto-imagen. Al final se realizó un último conversatorio sobre la experiencia en general.

Las categorías objeto de análisis se eligieron teniendo en cuenta la naturaleza de la investigación, el tema, los objetivos y el instrumento seleccionado. Se trabajaron tres grandes categorías, compuestas por otras subcategorías, así: 
Luz Marina Rodríguez Romero

Concepto-imagen: Identificación del concepto-imagen; Comprensión del mundo, de la naturaleza, del ser humano; Impacto emocional; Verdad y universalidad.

Categorías emergentes: Posicionamiento, Contextualización, Identificación.

Formas de pensamiento: Ruptura con la imagen dogmática del pensamiento, Linealidad del pensamiento, Capacidades.

\section{RESULTADOS}

\section{Análisis de las películas y las formas de pensamiento}

Cuadro 1. Análisis de las películas y las formas de pensamiento

\begin{tabular}{|l|l|l|c|}
\hline $\begin{array}{c}\text { Formas de pensamiento } \\
\text { Película }\end{array}$ & \multicolumn{1}{|c|}{ Pensamiento lineal } & $\begin{array}{l}\text { Rupturas con la imagen dogmática } \\
\text { del pensamiento }\end{array}$ & Capacidades \\
\hline & $\begin{array}{l}\text { Fragmentación de la } \\
\text { película } \\
\text { No identificación de un } \\
\text { La lengua de las } \\
\text { mariposas }\end{array}$ & $\begin{array}{l}\text { Ruptura con la narración lineal de } \\
\text { la película. } \\
\text { Problematización de las situaciones }\end{array}$ & $\begin{array}{c}\text { Reflexión } \\
\text { Contextualización } \\
\text { Pensamiento crítico. } \\
\text { Identificación }\end{array}$ \\
& $\begin{array}{l}\text { Dicotomáa. } \\
\text { Identificación de } \\
\text { personas buenas y malas. }\end{array}$ & $\begin{array}{l}\text { Duda, incertidumbre, preguntas } \\
\text { respecto de la película. } \\
\text { Conciencia de que no todas } \\
\text { las películas terminan con un final } \\
\text { feliz. }\end{array}$ & Relaciones \\
& Logopatía. & Inferencias \\
& & & \\
\hline
\end{tabular}




\begin{tabular}{|c|c|c|c|}
\hline $\begin{array}{l}\text { Batman, el caballero de } \\
\text { la noche }\end{array}$ & $\begin{array}{l}\text { Lógicas binarias } \\
\text { (bien y mal) }\end{array}$ & $\begin{array}{l}\text { Ruptura con la narración lineal de } \\
\text { la película. } \\
\text { Desarrollo de pensamiento crítico } \\
\text { con las situaciones de la película. } \\
\text { Presencia de la duda, la } \\
\text { incertidumbre y la pregunta. } \\
\text { Conciencia de que no todas las } \\
\text { películas terminan con un final feliz. } \\
\text { Problematización de las } \\
\text { situaciones de la película. } \\
\text { Ruptura con la lógica binaria. } \\
\text { Aparición de pensamiento } \\
\text { rizomático. } \\
\text { Duda e incertidumbre frente a los } \\
\text { planteamientos de la película. } \\
\text { Logopatía. }\end{array}$ & $\begin{array}{l}\text { Reflexión } \\
\text { Contextualización } \\
\text { Identificación } \\
\text { Argumentación } \\
\text { Relaciones } \\
\text { Inferencias }\end{array}$ \\
\hline Matrix & $\begin{array}{l}\text { Identificación con las } \\
\text { ideas del cristianismo } \\
\text { (Predestinación. Mesías) }\end{array}$ & $\begin{array}{l}\text { Duda e incertidumbre frente a los } \\
\text { planteamientos de la película. } \\
\text { Logopatía. }\end{array}$ & $\begin{array}{c}\text { Reflexión } \\
\text { Contextualización } \\
\text { Identificación } \\
\text { Argumentación } \\
\text { Relaciones } \\
\text { Inferencias }\end{array}$ \\
\hline Memento & $\begin{array}{l}\text { Descripción de } \\
\text { imágenes sin análisis ni } \\
\text { argumentación }\end{array}$ & $\begin{array}{l}\text { Ruptura con la narración lineal de } \\
\text { la película. } \\
\text { Desarrollo de pensamiento crítico } \\
\text { con las situaciones de la película. } \\
\text { Presencia de la duda, la } \\
\text { incertidumbre. } \\
\text { Problematización de las } \\
\text { situaciones de la película. } \\
\text { Ruptura con las lógicas binarias } \\
\text { del bueno y del malo. }\end{array}$ & $\begin{array}{l}\text { Reflexión } \\
\text { Contextualización } \\
\text { Identificación } \\
\text { Argumentación } \\
\text { Relaciones } \\
\text { Inferencias } \\
\text { Interpretar }\end{array}$ \\
\hline
\end{tabular}


En la lectura del cuadro 1 podemos señalar que las rupturas con la imagen dogmática del pensamiento son bastante significativas, en cuanto a la lectura lineal de las películas, a la ruptura con las lógicas binarias del pensamiento, a la problematización de los temas y a la aparición del pensamiento rizomático, derivado de la teoría filosófica de Gilles Deleuze y Félix Guattari. Para estos autores, un rizoma es un modelo descriptivo o epistemológico en el que la organización de los elementos no sigue líneas de subordinación jerárquica con una base o raíz, dando origen a múltiples ramas, sino que cualquier elemento puede afectar o incidir en cualquier otro; el rizoma carece, por lo tanto, de centro (1972, p. 13). En efecto, el pensamiento rizomático rompe con el pensamiento lineal y centrado, observado en el diagnóstico de la investigación, pues los estudiantes aplican un esquema tradicional al identificar personajes, trama, moraleja o enseñanza, o al identificar un único tema central, en tanto que con la aplicación del concepto-imagen aparecieron varias ideas-fuerza, las dudas, las incertidumbres y las preguntas que genera la observación de la película, así como la presencia de la logopatía, enunciada por Cabrera (1999, p. 20). Recordemos que la imagen dogmática dominante está compuesta por fuerzas que nos conducen a pensar de una forma determinada que imposibilita el pensamiento, como señala Deleuze (2002, p. 205). También se observa que en algunos de los estudiantes aún permanece la dualidad del bien y del mal, dentro de las características del pensamiento lineal y dogmático.

Pero, como es de esperar, esta propuesta pedagógica sobre cine y pensamiento es un proceso que no pretende hacer rupturas de un momento a otro, pero sí hacer fisuras o, por lo menos, propiciar esas rupturas a mediano o largo plazo mediante la práctica continua con los estudiantes. Esto al considerar que, como se reconoce, es muy difícil desaprender formas de pensamiento tradicional y lineal que han prevalecido durante siglos en la educación, mediante los modelos tradicionales caracterizados por la acumulación de información, el transmisionismo, los aprendizajes memorísticos, las relaciones verticales de poder y el logocentrismo, y que, lo más preocupante, en la escuela no se enseña a pensar, como lo señaló Zuleta (2004a, p. 23).

Por otra parte, cuando se hizo el análisis pertinente a cada película en cuanto a las categorías emergentes, como la contextualización, el posicionamiento y la identificación, se pudieron observar los niveles de argumentación de los estudiantes y las capacidades para inferir, 
relacionar, comprender, asociar, analizar e interpretar. También fue representativo lograr que los estudiantes conocieran y entendieran otros manejos del tiempo en las películas, diferentes al tiempo lineal, y que se enfrentaran a los finales no "felices", a la incomodidad, la duda y la incertidumbre que algunas de ellas les provocaron; como anota Cabrera (1999), la imagen cinematográfica es esencialmente desestructuradora, desestabilizadora, subversiva.

Por lo anterior, se puede colegir que el ejercicio con el concepto-imagen, como una propuesta de cambio en las prácticas pedagógicas universitarias, es una manera de formar a los estudiantes como personas reflexivas y críticas, es una forma de resistencia frente a las políticas educativas del Estado, relacionadas con el capitalismo cognitivo, que adiestra para la producción del conocimiento como un valor inmaterial, como un dispositivo de control y de poder, como lo anota Mejía (2009), formando en la competencia, utilizando a las personas como un medio y no como un fin.

\section{Análisis del concepto-imagen en las películas observadas}

Cuadro 2. Análisis del concepto-imagen en las peliculas observadas

\begin{tabular}{|l|l|l|l|l|}
\hline \multicolumn{1}{|c|}{ Película } & \multicolumn{1}{|c|}{$\begin{array}{c}\text { Concepto- } \\
\text { imagen }\end{array}$} & Comprensión del mundo & \multicolumn{1}{|c|}{ Impacto emocional } & \multicolumn{1}{c|}{ Verdad y universalidad } \\
\hline $\begin{array}{l}\text { La lengua } \\
\text { de las } \\
\text { mariposas }\end{array}$ & No se realizó & $\begin{array}{l}\text { Del ser humano determina- } \\
\text { do por los dogmas. } \\
\text { Rol del maestro en la socie- } \\
\text { dad. }\end{array}$ & $\begin{array}{l}\text { Llanto, tristeza, dolor } \\
\text { e impotencia ante la } \\
\text { injusticia. }\end{array}$ & $\begin{array}{l}\text { Posibilidad de desarrollar seres } \\
\text { con capacidad crítica. } \\
\text { Alegría ante el ejemplo del } \\
\text { maestro como ser humano. } \\
\text { Dolor ante la pérdida de un ser } \\
\text { querido, víctima de la represión. }\end{array}$ \\
$\begin{array}{l}\text { El poder de la religión como } \\
\text { dispositivo de control. } \\
\text { negligencia de algunas } \\
\text { La de } \\
\text { personas ante la injusticia. }\end{array}$ \\
\hline
\end{tabular}




\begin{tabular}{|c|c|c|c|c|}
\hline $\begin{array}{l}\text { Batman, el } \\
\text { caballero de la } \\
\text { noche }\end{array}$ & $\begin{array}{l}\text { Moral-valores } \\
\text { Poder } \\
\text { Maltrato como } \\
\text { historia de vida y } \\
\text { desencadenante de } \\
\text { violencia } \\
\text { Las mafias como } \\
\text { modo de violencia } \\
\text { El narcotráfico } \\
\text { El amor } \\
\text { La violencia } \\
\text { La justicia } \\
\text { La injusticia o } \\
\text { ilegalidad } \\
\text { Justicia y verdad } \\
\text { Lucha entre el bien } \\
\text { y el mal } \\
\text { La mentira } \\
\text { La mentira- } \\
\text { esperanza }\end{array}$ & $\begin{array}{l}\text { El poder está relacionado con } \\
\text { la violencia. } \\
\text { Existe un poder negativo y otro } \\
\text { positivo. } \\
\text { El poder demanda inteligencia } \\
\text { y astucia para hacer estrategias. } \\
\text { La bondad y la maldad } \\
\text { subyacen en todas las personas. } \\
\text { Respetar la vida de los demás } \\
\text { o preservar la propia es un } \\
\text { dilema. } \\
\text { Las organizaciones del crimen } \\
\text { son estructuradas y poderosas. } \\
\text { La mentira puede tener buenas } \\
\text { intenciones pero siempre será } \\
\text { mentira. } \\
\text { La guerra y la auto-destrucción } \\
\text { como consecuencias del poder. } \\
\text { El dinero no es todo en la vida. } \\
\text { El verdadero amor es una } \\
\text { entrega desinteresada y asume } \\
\text { riesgos. }\end{array}$ & $\begin{array}{l}\text { Tristeza porque el héroe se } \\
\text { declara culpable. } \\
\text { Ansiedad por no saber cómo } \\
\text { actúa el Guasón } \\
\text { Impotencia ante la maldad. } \\
\text { Felicidad porque el Guasón no } \\
\text { se salió con la suya. } \\
\text { Enojo por la actitud de los } \\
\text { ciudadanos de Gótica. } \\
\text { Emoción por las imágenes } \\
\text { espectaculares de los efectos } \\
\text { especiales. } \\
\text { Miedo ante la muerte. } \\
\text { Miedos que no se han } \\
\text { enfrentado. } \\
\text { Tristeza y rabia por dejar la vida } \\
\text { de las personas al azar. } \\
\text { Desespero por la maldad sin } \\
\text { límites. } \\
\text { Tristeza por la muerte de } \\
\text { inocentes. }\end{array}$ & $\begin{array}{l}\text { Los concepto-imagen expuestos, } \\
\text { tienen un sentido de universalidad } \\
\text { y verdad, para definirse como tales, } \\
\text { porque las situaciones le pueden } \\
\text { ocurrir a cualquiera y porque le dan } \\
\text { sentido al componente logopático, } \\
\text { según Cabrera. }\end{array}$ \\
\hline
\end{tabular}




\begin{tabular}{|c|c|c|c|c|}
\hline Matrix & $\begin{array}{l}\text { Lo real y lo irreal } \\
\text { El amor } \\
\text { Realidades } \\
\text { La historia } \\
\text { La verdad } \\
\text { El poder } \\
\text { La fe } \\
\text { Mundos paralelos }\end{array}$ & $\begin{array}{l}\text { El poder de las máquinas. } \\
\mathrm{La} \text { existencia de varias } \\
\text { realidades y mundos paralelos. } \\
\text { El valor del ser humano } \\
\text { como tal. } \\
\mathrm{La} \text { necesidad de creer en } \\
\text { algo o en alguien. } \\
\text { El amor como una fuerza } \\
\text { que mueve la vida. } \\
\text { El poder de la mente. } \\
\text { La verdad como sentido de } \\
\text { la existencia. } \\
\text { La importancia de la historia } \\
\text { para el conocimiento de la } \\
\text { realidad presente y futura. }\end{array}$ & $\begin{array}{c}\text { Angustia } \\
\text { Miedo } \\
\text { Alegría } \\
\text { Impotencia } \\
\text { Tristeza } \\
\text { Desconcierto }\end{array}$ & $\begin{array}{l}\text { Los concepto-imagen } \\
\text { expuestos, tienen un sentido } \\
\text { de universalidad y verdad, para } \\
\text { definirse como tales, porque } \\
\text { las situaciones le pueden } \\
\text { ocurrir a cualquiera y porque } \\
\text { le dan sentido al componente } \\
\text { logopático, según Cabrera. }\end{array}$ \\
\hline Memento & $\begin{array}{l}\text { Tatuajes } \\
\text { Escribir en las } \\
\text { fotografías } \\
\text { Escritura } \\
\text { Mentira } \\
\text { Olvido } \\
\text { Amor-odio } \\
\text { La fragilidad } \\
\text { humana } \\
\text { ¿Qué somos, } \\
\text { fantasía o } \\
\text { realidad? } \\
\text { Las fotografías y } \\
\text { mensajes como } \\
\text { elementos del } \\
\text { recuerdo } \\
\text { Venganza } \\
\text { Creer }\end{array}$ & $\begin{array}{l}\text { La escritura como una } \\
\text { forma para recordar y para } \\
\text { sobrevivir. } \\
\text { Importancia de la mente y } \\
\text { la memoria en la vida del } \\
\text { ser humano. } \\
\text { A veces la mentira es } \\
\text { necesaria para poder vivir. } \\
\text { La fragilidad del ser humano } \\
\text { al perder la memoria. } \\
\text { La importancia de creer en } \\
\text { el mundo externo. }\end{array}$ & $\begin{array}{c}\text { Incertidumbre } \\
\text { Desconfianza } \\
\text { Duda } \\
\text { Terror } \\
\text { zozobra } \\
\text { Confusión } \\
\text { Expectativa }\end{array}$ & $\begin{array}{l}\text { Los concepto-imagen expues- } \\
\text { tos tienen un sentido de univer- } \\
\text { salidad y verdad, para definirse } \\
\text { como tales, porque las situacio- } \\
\text { nes le pueden ocurrir a cual- } \\
\text { quiera y porque le dan sentido al } \\
\text { componente logopático, según } \\
\text { Cabrera. }\end{array}$ \\
\hline
\end{tabular}


Como se puede observar en el cuadro 2, la identificación del concepto-imagen en las películas se fue consolidando a partir de la segunda película, ya que en La lengua de las mariposas no se realizó, pues para los estudiantes no quedó muy claro este concepto y mas bien focalizaron el trabajo en la identificación y descripción de algunos elementos técnicos, como los planos y los movimientos de cámara; por esta razón fue necesario explicar de nuevo, mediante un ejemplo, la definición de concepto-imagen. Estas circunstancias responden a un proceso de asimilación que es natural cuando se realizan innovaciones y cambios; en este caso, como se planteaba con anterioridad, se trata de fisuras, que poco a poco devienen en rupturas.

También se puede deducir que el trabajo de identificación con el concepto-imagen se fue consolidando en cada una de las películas, alrededor de las problemáticas que se planteaban en ellas; como se trata de experiencias individuales y particulares, la focalización es diversa, aunque se nota una tendencia a identificar los valores y los antagonismos en cada una de las narraciones. Un concepto-imagen común en todas las películas fue el amor.

Además, se pudo observar una ruptura con la tradición de llevar el cine al aula de clase como una forma de complementar las temáticas de las diversas disciplinas, pre-determinando la focalización del estudiante, sin tener en cuenta la complejidad de las películas; o tomarlas como un texto más, o como cine "porno" (por no hacer clase), que es muy común ver en el ámbito académico. También es significativo que quedó atrás el contar la "anécdota" o "el mensaje" o "moraleja", pues las películas se problematizaron para dar paso al análisis y la reflexión, a la posibilidad de pensar, indagar y dudar.

Respecto de la comprensión del mundo, uno de los componentes que definen el concepto-imagen y que se tomó como una subcategoría para este análisis, se puede expresar que a través del trabajo de argumentación y análisis se identificaron varios niveles de comprensión del mundo, de la naturaleza y del ser humano en su relación con los otros; se evidencia una comprensión de las tensiones, las dicotomías, los roles de los personajes en relación con el mundo de la vida en conjunción con las emociones. Aquí también es posible notar la diversidad y la riqueza de componentes de las películas susceptibles de comprensión por parte de los estudiantes, en sus dimensiones cognitiva, filosófica y ética, a partir de las situaciones problematizantes que presentan. 
En cuanto al impacto emocional que producen las imágenes del cine, se infiere que, en la primera película, La lengua de las mariposas, la expresión de las emociones por los estudiantes no es muy explícita, teniendo en cuenta que en el ámbito académico se ha hecho una escisión entre la lógica y la emoción; no es común que en el aula de clase se expresen emociones respecto de los contenidos de las disciplinas; aún más, es una debilidad o una muestra de la vulnerabilidad en público, no se habla de lo que se siente, aunque sí fue evidente la risa en algunas ocasiones y también la expresión de dolor y conmoción de las últimas escenas de la película. Como en las anteriores subcategorías, se hace explícita la consolidación del trabajo con este componente del concepto-imagen; además, si se tiene en cuenta que la experiencia compartida fue ampliando los niveles de confianza, pues se logró un cambio en las relaciones comunicativas lineales entre los estudiantes y la docente a partir de los diálogos y el ambiente que propiciaron las películas. De esta manera, las emociones que produjeron cada una de las películas se compartieron y se argumentaron, de acuerdo con los contenidos de ellas. En La lengua de las mariposas se expresaron sentimientos de tristeza y de alegría; en Matrix y en Batman se denota la impotencia, el miedo, la incertidumbre y la ansiedad, y en Memento, la duda, la confusión, la expectativa, el miedo y la incertidumbre; emociones articuladas o estrechamente relacionadas con el ejercicio lógico, analítico, argumentativo y comprensivo, es decir, la logopatía de la que habla Cabrera (1999, p. 20).

Por último, el componente de verdad y de universalidad en el concepto-imagen se validó, a través de la argumentación, la comprensión y la emoción que expresaron los estudiantes, por el hecho de que las situaciones que presentan las cuatro películas le pueden suceder a cualquiera, como también lo ha definido Cabrera en su teoría.

\section{Análisis de las categorías emergentes en las películas}

\section{Cuadro 3. Análisis de las categorías emergentes en las películas}

\begin{tabular}{|c|c|c|c|}
\hline Película & Posicionamiento & Contextualización & Identificación \\
\hline La lengua de las mariposas & $\begin{array}{l}\text { Frente al poder alienante de } \\
\text { la política y la Iglesia. } \\
\text { Frente a la idea del castigo y } \\
\text { la recompensa. } \\
\text { Frente a la tolerancia y el } \\
\text { respeto por las ideas de los } \\
\text { otros. }\end{array}$ & $\begin{array}{l}\text { Con la situación política de } \\
\text { Colombia, la lucha entre } \\
\text { liberales y conservadores. } \\
\text { Con el asesinato de líderes } \\
\text { como Jesucristo, Gaitán, Galán, } \\
\text { Jaime Garzón. }\end{array}$ & $\begin{array}{l}\text { Con la propia infancia. } \\
\text { Con ser estudiantes y futuros } \\
\text { maestros. } \\
\text { Con ponerse en el lugar del } \\
\text { otro. } \\
\text { Con la lucha por lo que se } \\
\text { quiere. }\end{array}$ \\
\hline
\end{tabular}




\begin{tabular}{|c|c|c|c|}
\hline $\begin{array}{c}\text { Batman, el caballero de la } \\
\text { noche }\end{array}$ & $\begin{array}{l}\text { Frente a las mentiras } \\
\text { piadosas. }\end{array}$ & $\begin{array}{l}\text { Con la realidad social y política } \\
\text { del país relacionada con la } \\
\text { violencia de la guerrilla, el } \\
\text { paramilitarismo, el narcotráfico, } \\
\text { la impunidad y la corrupción. }\end{array}$ & $\begin{array}{l}\text { Con la nobleza y el amor de } \\
\text { Batman. } \\
\text { Situación de ambivalencia en } \\
\text { Dent. }\end{array}$ \\
\hline Matrix & . & $\begin{array}{l}\text { Con la situación de dependencia. } \\
\text { Sometimiento y esclavitud de } \\
\text { América Latina. } \\
\text { Con los héroes de la película } \\
\text { relacionados con los héroes de la } \\
\text { independencia latinoamericana. } \\
\text { Con el cristianismo (Mesías) } \\
\text { Con el uso de la tecnología en la } \\
\text { vida cotidiana. } \\
\text { Con la realidad de las clases } \\
\text { sociales. }\end{array}$ & Situación de decidir por otro. \\
\hline Memento & Frente a la mentira & $\begin{array}{l}\text { Realidad social (discriminación). } \\
\text { Vida cotidiana. }\end{array}$ & $\begin{array}{l}\text { Con el protagonista y la } \\
\text { situación de perder la memoria. }\end{array}$ \\
\hline
\end{tabular}

Las categorías emergentes que aparecieron en las narrativas de los textos escritos por los estudiantes, relacionadas con la posición o el punto de vista de ellos no fueron muy explícitas; parece que esa particularidad, que tiene que ver con lo político, no ha sido muy elaborada; solamente en La lengua de las mariposas, algunos de los estudiantes asumieron su posición frente al poder alienante de la Iglesia y de las ideologías, frente a la idea del castigo y la recompensa y frente al respeto por la diferencia. En las películas Batman: el caballero de la noche y Memento fijaron su posición respecto de la mentira, en concordancia con los valores y la ética. En este sentido, se logró que los estudiantes pensaran por sí mismos, se pusieran en el lugar del otro, de acuerdo con Zuleta, en la exposición del problema de esta investigación.

La subcategoría de la contextualización fue quizá la de más relevancia y desarrollo en esta experiencia. Se aprecia en todas las películas la manera de contextualizar la realidad de la ficción con la realidad social y política del país a lo largo de su historia, en cuanto a la violencia, el uso 
del poder, la discriminación, el asesinato de líderes políticos, la alienación de América Latina, la desigualdad en las clases sociales, la impunidad y la corrupción, como una metáfora, y en algunos casos como una abstracción, en la película Matrix. Por lo anterior, se infiere que los estudiantes tienen un alto grado de conciencia de la situación contextual para poderla relacionar con las ficciones de las películas.

En cuanto a la identificación con las situaciones y los personajes de las películas, los estudiantes se identificaron con situaciones personales de la infancia y de los roles como maestro y estudiante, en el caso de La lengua de las mariposas; con la personalidad de Dent y de Batman, con la situación de perder la memoria en Memento, es decir, con la posibilidad de ponerse en el lugar del otro, de comprender al otro en tanto seres humanos provistos de valores, pero también de defectos, en situaciones de tensión y desventaja.

\section{Análisis de la dimensión comunicativa}

Cuadro 4. Análisis de la dimensión comunicativa en el ejercicio del análisis de las películas

\begin{tabular}{|c|c|c|c|}
\hline Película & Visual & Escrita & Oral \\
\hline La lengua de las mariposas & $\begin{array}{l}\text { Identificación de lenguaje } \\
\text { cinematográfico (planos, } \\
\text { movimientos de cámara, } \\
\text { secuencias, escenas, iluminación, } \\
\text { música). } \\
\text { Lectura de imágenes en } \\
\text { movimiento. }\end{array}$ & $\begin{array}{l}\text { Construcción de texto } \\
\text { escrito } \\
\text { Argumentación } \\
\text { Análisis } \\
\text { Contextualización } \\
\text { Identificación }\end{array}$ & $\begin{array}{l}\text { Comunicabilidad } \\
\text { Confianza. } \\
\text { Participación } \\
\text { Interacción } \\
\text { Empatía } \\
\text { Espontaneidad } \\
\text { Emergencia de otros elementos } \\
\text { en cuanto a sensibilidad, } \\
\text { percepción y pensamiento }\end{array}$ \\
\hline
\end{tabular}




\section{Luz Marina Rodríguez Romero}

\begin{tabular}{|c|c|c|c|}
\hline Batman, el caballero de la noche & $\begin{array}{l}\text { Identificación de lenguaje } \\
\text { cinematográfico (planos, } \\
\text { movimientos de cámara, } \\
\text { secuencias, escenas, iluminación, } \\
\text { música, efectos especiales). } \\
\text { Lectura de imágenes en } \\
\text { movimiento. }\end{array}$ & $\begin{array}{l}\text { Construcción de texto } \\
\text { escrito } \\
\text { Argumentación. } \\
\text { Análisis } \\
\text { Contextualización } \\
\text { Identificación }\end{array}$ & $\begin{array}{l}\text { Comunicabilidad } \\
\text { Confianza } \\
\text { Participación } \\
\text { Interacción } \\
\text { Empatía } \\
\text { Espontaneidad } \\
\text { Emergencia de otros elementos } \\
\text { en cuanto a sensibilidad, } \\
\text { percepción y pensamiento }\end{array}$ \\
\hline Matrix & $\begin{array}{l}\text { Identificación de lenguaje } \\
\text { cinematográfico (planos, } \\
\text { movimientos de cámara, } \\
\text { secuencias, escenas, } \\
\text { iluminación, música, efectos } \\
\text { especiales). } \\
\text { Lectura de imágenes en } \\
\text { movimiento. }\end{array}$ & $\begin{array}{l}\text { Construcción de texto } \\
\text { escrito } \\
\text { Argumentación } \\
\text { Análisis } \\
\text { Contextualización } \\
\text { Identificación }\end{array}$ & $\begin{array}{l}\text { Comunicabilidad } \\
\text { Confianza. } \\
\text { Participación } \\
\text { Interacción } \\
\text { Empatía } \\
\text { Espontaneidad } \\
\text { Emergencia de otros elementos } \\
\text { en cuanto a sensibilidad, } \\
\text { percepción y pensamiento }\end{array}$ \\
\hline Memento & $\begin{array}{l}\text { Identificación de lenguaje } \\
\text { cinematográfico (planos, } \\
\text { movimientos de cámara, } \\
\text { secuencias, escenas, iluminación, } \\
\text { música, efectos especiales). } \\
\begin{array}{l}\text { Lectura de imágenes en } \\
\text { movimiento. }\end{array}\end{array}$ & $\begin{array}{l}\text { Construcción de texto } \\
\text { escrito } \\
\text { Argumentación } \\
\text { Análisis } \\
\text { Contextualización } \\
\text { Identificación }\end{array}$ & $\begin{array}{l}\text { Comunicabilidad } \\
\text { Confianza. } \\
\text { Participación } \\
\text { Interacción } \\
\text { Empatía } \\
\text { Espontaneidad } \\
\text { Emergencia de otros elementos } \\
\text { en cuanto a sensibilidad, } \\
\text { percepción y pensamiento }\end{array}$ \\
\hline
\end{tabular}


La dimensión comunicativa que se desarrolló en este trabajo es quizá otro de los aspectos más significativos. Como lo presenta el cuadro, en todas las películas se logró un conocimiento de aspectos básicos y elementales de la técnica cinematográfica, articulados con el trabajo del concepto-imagen a partir del ejercicio visual, de lectura y comprensión de imágenes y musicalización, que en un comienzo acaparó el interés de los estudiantes, en el caso de La lengua de las mariposas, como se expresó con anterioridad.

El ejercicio de la producción textual fue resultado del estímulo de las películas acompañadas del trabajo con el concepto-imagen. Es representativa la cantidad y la calidad que se registró en la producción escrita de los estudiantes, a diferencia de la dificultad y las formas esquemáticas que presentan los textos cuando se trata de otro tipo de experiencias con el ejercicio de la escritura en la universidad. En general, el nivel de argumentación y de coherencia fue sobresaliente, de acuerdo con el desarrollo de las capacidades en los procesos de lectura y de escritura de cada uno de los estudiantes. Aunque hubo momentos en que se presentó alguna resistencia a la escritura, por el trabajo y el tiempo que implicaba y por los deberes académicos, en especial en el periodo de evaluaciones, hecho notorio en la producción escrita para la última película, Memento, en general hubo una buena disposición para la escritura.

La dimensión oral dentro de esta experiencia comunicativa fue definitiva, por cuanto la socialización en los conversatorios permitió que emergieran otros aspectos que por las exigencias de la escritura a veces se escapan, y que, según los estudiantes, es más fácil conversarlos, por la espontaneidad que genera la oralidad.

En concordancia con los otros aspectos involucrados en el proceso de la innovación, la participación en los conversatorios se fue acrecentando con el transcurrir de cada experiencia y de cada película. La interacción, la confianza, los sentimientos de empatía entre estudiantes y docente enriquecieron el trabajo y lograron hacer rupturas en las prácticas pedagógicas en el aula de clase y en las relaciones comunicativas tradicionales que establecen diferencias jerárquicas. 


\section{Conversatorio final}

El conversatorio final enriqueció en gran medida el trabajo con el concepto-imagen; los temas que se desarrollaron estuvieron relacionados con la experiencia en general, los conversatorios, las experiencias de ver cine en otras clases y el trabajo con el concepto-imagen. Estas fueron algunas de las reflexiones de los estudiantes:

Respecto de la experiencia en general: Esta experiencia permite el análisis, la interpretación y la comprensión de la realidad a partir de la película; permite crear hábitos y ver la película no solo por diversión, sino ir más allá del sentido del cine. Al retomar la película para hacer el concepto-imagen se aprende qué es el cine. La escritura sirve para organizar las ideas. Lo que más les gustó: las películas.

Respecto de los conversatorios: Los conversatorios permiten abrir el espacio para compartir el punto de vista personal y complementar con lo que dijeron los compañeros en una comunicación más directa; por la confianza que se establece, sirvieron para descubrir nuevos elementos de las películas y expresar oralmente lo que se piensa, para interpretar la vida, para tener un sentido más pedagógico de ver el cine; de esta manera, se aprenden múltiples enseñanzas, mensajes, moralejas, y se vive una experiencia de ponerse en el lugar del otro, no solo alrededor del resumen, como se hace en otras clases. Mediante los conversatorios se le saca más jugo a la película.

Respecto del concepto-imagen: Es difícil identificarlo y relacionarlo con los planos. En Matrix fue difícil identificar el concepto-imagen. Mediante el concepto-imagen se comprende que el cine es sentir y comprender algo, porque la imagen tiene un significado. Con el trabajo del concepto-imagen, el significado de la película es más fuerte.

El cine en las otras clases: En otras clases solo se trata de hacer un resumen, un análisis, un "ensayo", que generalmente se baja de Internet. Otro aspecto significativo es que solo ven una o dos películas en el semestre. Esta experiencia es una novedad en Psicopedagogía. 


\section{CONCLUSIONES}

Después de esta experiencia investigativa y de innovación pedagógica sobre el cine como una estrategia para desarrollar el pensamiento se puede concluir:

El concepto de innovación pedagógica se ha tomado en este trabajo como una fisura, en connivencia con el concepto de muchos otros investigadores, de acuerdo con lo señalado por Blanco y Messina en el estado del arte sobre las innovaciones en América Latina. En este caso particular, las rupturas se hicieron en cuanto a la forma como se enseña a pensar a los estudiantes por medio de la observación del cine, como resistencia ante las prácticas pedagógicas que en el sistema tradicional se han reducido a la transmisión y al adiestramiento en competencias para la producción de conocimiento como un nuevo valor del capitalismo cognitivo (Mejía, 2009).

Más allá de llevar el cine al aula de clase para relacionarlo con las temáticas de las disciplinas, como una herramienta para la enseñanza-aprendizaje, o para someter las películas a análisis esquemáticos, como en los modelos tradicionales, sin tener en cuenta la complejidad que encierran muchas de ellas, se logró trabajar el cine como una estrategia para provocar rupturas y fisuras en las formas del pensamiento dogmático, lineal y tradicional que la educación ha marcado en los estudiantes y los maestros; pensamiento dogmático caracterizado por fuerzas que llevan a pensar de manera determinada, a concebir la idea de la verdad como fundamento, más que en provocar situaciones que lleven a indagar por la verdad, es decir, en palabras de Zuleta, a enseñar a pensar o a propiciar espacios pedagógicos con este propósito.

Las rupturas con la imagen dogmática del pensamiento, que se observaron a través del ejercicio con el concepto-imagen propuesto por Julio Cabrera, y se enunciaron en los conversatorios y en los textos escritos por los estudiantes, están en correspondencia con la producción de otras formas de pensamiento distintas a las determinadas. Parte de estas rupturas es el fortalecimiento de la conciencia acerca de que existen fuerzas externas que, con sus dogmas, impiden el desarrollo del pensamiento, y el distanciamiento de las lógicas binarias del pensamiento tradicional, que crean antagonismos, polarización y verdades a priori. Las películas, a través de los personajes, los diálogos y las acciones, permitieron crear dudas, interrogantes e incertidumbre acerca de verdades establecidas, para generar un pensamiento reflexivo y crítico, articulado con la realidad de los contextos educativos, políticos, sociales y culturales. 
También se logró romper con el resumen lineal de las anécdotas de las películas, de la identificación de personajes principales y secundarios, de la enseñanza o moraleja, al encontrase con películas que rompen con la estructura lineal del tiempo en sus narraciones; de esta manera se hizo evidente la aparición de otro tipo de pensamiento, del pensamiento rižomático, propuesto por Deleuze, caracterizado por la ruptura con la raíz principal y única de los conceptos a priori o predeterminados, en contraste con el descentramiento y la multiplicidad de conceptos y miradas respecto de las películas y las situaciones que allí se presentan. Este logro fue posible al hacer un análisis de las películas a partir de varios concepto-imagen o ideas-fuerza, en conjunción con las emociones y la razón o logopatía de la que habla Cabrera, que en el sistema educativo actual es tan necesario introducir. En otras palabras, se logró la problematización de las películas al ser confrontadas con los imaginarios y las creencias de los estudiantes. Así pues, como anota Badiou, el cine ha creado una ruptura, al crear un lazo íntimo entre su aparición y las formas posibles de pensamiento.

El cine, como estrategia para desarrollar el pensamiento a partir del concepto-imagen y la logopatía, se constituyó en una práctica de, con y para los sujetos involucrados, en este caso los estudiantes y la docente, con la perspectiva de que se pueda potenciar para la realización de prácticas pedagógicas críticas y reflexivas aplicadas en otros contextos educativos, sociales y culturales. En forma simultánea, esta experiencia se puede considerar una estrategia-dispositivo que posibilita prácticas pedagógicas innovadoras a partir de su diseño y ejecución, de la que resultaron fisuras y rupturas con la imagen dogmática del pensamiento presente en las estructuras tradicionales de la educación, visibles en las prácticas pedagógicas pensadas para la transmisión y la formación en competencias de producción, en las didácticas instrumentales, en las relaciones de orden jerárquico, las cuales se visibilizan también en los sujetos en formación a través de sus formas de pensamiento, en sus discursos y en sus acciones.

El rol de la docente en esta experiencia fue más allá de acompañar y de guiar el trabajo de los estudiantes, pues se involucró como sujeto-maestra en ejercicio, al participar de la reflexión y del diálogo no solamente con los estudiantes y las películas, sino sobre sus propias prácticas pedagógicas, en una especie de monitoreo sobre el proceso de la innovación, sobre sus dificultades, desaciertos y los logros, para afinar su percepción sobre la conjunción entre pedagogía, cine y pensamiento, como una forma de expandir su identidad como educadora comprometida con la formación de personas críticas, que puedan pensar por sí mismas, y para dar sentido a sus propias prácticas. 
Esta experiencia, además, permitió hacer rupturas en el sentido de que el maestro se re-conoce a sí mismo como educador y formador, más allá de ser mero instructor o transmisor de un saber específico, y a la vez re-conocer a los estudiantes como seres que piensan, experimentan y comunican emociones.

Uno de los logros a nivel de la innovación fue crear espacios de encuentro entre la docente y los estudiantes a través de la participación y la interacción en los conversatorios en un ambiente de confianza y empatía generado por la motivación de las películas, pues estos encuentros no estaban determinados por el control de la calificación, sino por el deseo personal; de esta manera se hizo una ruptura con los modelos lineales de comunicación, caracterizados por relaciones de poder y de intimidación en los que la voz la tiene el profesor, y los estudiantes son receptores.

Por otra parte, el ejercicio con la escritura fue bastante significativo, por su calidad en la argumentación, la capacidad de contextualizar, analizar e interpretar; si se tiene en cuenta que estas prácticas son una de las falencias en el ámbito universitario. En consecuencia, se dio apertura a procesos dialógicos tan esenciales en la formación de las personas, advertido por Freire en sus propuestas pedagógicas y sociales.

Otra bondad de esta innovación fue la apertura hacia otras estrategias didácticas y pedagógicas, como el cine, en respuesta a las exigencias y necesidades de la época actual, referidas a la cultura de la tecnología, a la cultura iconográfica, a la que han dedicado sus estudios Ferrés y MacLuhan, y a la crítica que ha formulado Martín Barbero a la cultura logocéntrica en la educación.

El enfoque socio-crítico del trabajo de investigación se logró desarrollar por cuanto se trabajó sobre unos supuestos teóricos fundamentados por los autores y las teorías que acompañaron el proceso, y se generó un compromiso por parte de estudiantes y la docente-investigadora respecto de un cambio y una emancipación frente a la problemática planteada, como una forma de resistencia ante la imagen dogmática del pensamiento que subyace en la educación, y todo lo que esto determina.

A pesar del corto tiempo para la aplicación de la propuesta innovadora, se observaron unos cambios, unas fisuras y unas rupturas en las formas del pensamiento de los estudiantes, por lo que se vislumbra que esta semilla se convirtió en un fortalecimiento para su formación como personas y futuros profesionales de la educación, al pensar por sí mismos, ser críticos y reflexivos frente a la realidad. 


\section{REFERENCIAS}

Badiou, A. (2004). "El cine como experimentación filosófica". En Yoel, Gerardo (Comp.): Pensar el cine 1. Imagen, ética y filosofía. Buenos Aires: Manantial.

Barbero, J. M. (2003). "Retos culturales de la comunicación en la educación. Elementos para una reflexión que está por comenzar". En: Morduchowicz, Roxana (Coord.): Comunicación, medios y educación, un debate para la educación en democracia. España: Octaedro.

Blanco R. y Messina G. (2000). Estado del arte sobre las innovaciones educativas en América Latina. Bogotá: Convenio Andrés Bello.

Deleuze, G. (2000). Nietzsche. Madrid: Arena Libros.

Deleuze G. y Guattari, F. (1972). Mil mesetas. España: Pre-textos.

De La Torre, S. (1997). Innovación educativa. Madrid: Dykinson.

Cabrera, J. (1999). Cine: cine años de filosofía. Barcelona: Gedisa.

Freinet, C. (1974). Las técnicas audiovisuales. Barcelona: Laia.

Ferrés, J. (1993). Video y educación. Barcelona: Paidós.

Ferrés, J. (2000). Educar en una cultura del espectáculo. Barcelona: Paidós.

McLuhan, M. (1969). La comprensión de los medios como extensiones del hombre. México: Diana.

Mejía, M. R. (2008). El nuevo capitalismo cognitivo. Lecturas de la Maestría en Educación. Uptc.

Torres, E. (1999). Una pasión hecha proyecto. Vida de maestro. Volumen II, IDEP, Bogotá.

Zuleta, E. (2004a). Educación y democracia. Medellín: Hombre Nuevo Editores.

Zuleta E. (2004b). Elogio de la dificultad. Medellín: Hombre Nuevo Editores. 